\title{
Polyurethane in Urological Practice
}

\author{
Valentina Cauda and Furio Cauda
}

Additional information is available at the end of the chapter

http://dx.doi.org/10.5772/36408

\section{Introduction}

Polyurethane (PU) is one of the most bio- and blood-compatible materials currently used for fabrication of various medical devices, e.g. blood bags, vascular/ureteral catheters and artificial heart. Originally, PU was conceived with other copolymers, aiming at similar goals, i.e. enough versatility to successfully meet biomedical devices constraints, such as biocompatibility, resistance to sterilization, physical features invariance over time and infection resistance during indwelling. PU in particular, has also other key properties particularly suited to biomedical industry, including strength, versatility and low cost. The surface of PU can be chemically functionalized with organic and biologically active molecules, resulting in improved durability, compliance, acceptance and tolerance in the human body during implantation. These features additionally strengthen PU as an appealing candidate for biomedical applications.

Normally, several polymers such as natural rubber, polyethylene, polyvinylchloride, fluoropolymers, hydrogels and silicon are used in biomedical applications. Despite the widespread use of these materials, PU still covers a relevant and dominant role, thanks to its high blood and tissue biocompatibility for improving the quality of patient's life. It conjugates a good stability over long implantation times, excellent physico-mechanical and surface tuning properties via anchoring of molecules. PU has simply a unique mix of features, highly required for almost any medical device.

PU is also widely used in cardiovascular applications, in particular for the preparation of venous and intravenous catheters and balloons for angioplasty and angiography. It has also been successfully used for tissue replacement and augmentation in breast implants, facial reconstruction and body joints. Artificial organs based on PU such as heart, kidneys and lungs have already been developed. Thanks to its above described unique features, PU has recently been proposed for new promising application fields, e.g. controlled drug delivery devices. A deep review on the use of PU in medicine and medical devices is also available (Zdrahala and Zdrahala 1999). 
Given its large use, in this chapter we will focus on the use of PU in urological applications, in particular as ureteral catheter, or stent, in endourology routines.

In urology, catheterization is defined as the insertion of tubes (stents), such as urinary catheters, into the patient's bladder through the urethra. A stent is usually a tube with ending coils at both sides (pig-tails), or with lateral holes to further improve urine drainage (JJ or double-J). Urethral stents are usually in latex, silicone or polyurethane, allowing patients' urine to drain freely from the bladder. Stents can also be used to inject liquids for treatment or bladder conditions diagnosis. A patient is typically catheterized in the case of acute or chronic urinary retention, orthopedic procedures that may limit movement, benign prostatic hyperplasia, incontinence, and effects of various surgical interventions involving bladder and prostrate.

In endourology, urine is drained by indwelling a catheter between the kidney and the patient's bladder, hence inserting the stent into the ureter. Nowadays, ureteral stenting has become a common procedure for safe urine drainage. It is effective for managing several diseases, such as ureteral obstruction by stones or clots, benign or malignant ureteral obstruction, or post-surgical treatments, i.e. ureteroscopy and ureteral surgery. Ureteral stents almost painlessly keep the ureteral lumen open, ensuring that urine flows while maintaining the correct renal function. Stents also promote ureteral healing and prevent strictures formation.

From a general urological viewpoint, these devices must be easily maneuverable, affordable, and radiopaque for a correct positioning under fluoroscopic guidance. Hence, ureteral stents are mainly fabricated in PU or silicone since some patients can be allergic or sensitive to latex after long-term use. Radiopacity is ensured by adding metallic salts, e.g. based on barium. According to a critical study on materials (Mardis et al. 1993), the use of strong materials, e.g. PU, permits the reduction of the stent wall thickness, enlarging the inner lumen and the size or number of lateral holes and increasing urine flow. Silicone stents are weaker than PU, and need to be fabricated with smaller inner diameters, compromising urine flow and increasing the lateral compressibility.

Despite the numerous advantages enabled by PU, some complications and challenges remain. Indeed, PU is not perfectly biocompatible, in the sense that it somehow affects the epithelial cells of the ureter (urothelium): urothelial ulceration and erosion may occur. Other complications are related to stent migration or fracture, erosion, development of ureteroarterial fistula, fever, infection, voiding symptoms including dysuria and hematuria (Arshad et al. 2006). Among these, the stent encrustation represents one of the most serious complications resulting from the use of PU double-J stents: a stent can be encrusted by inorganic salts flowing with urine, and bacterial colonies can grow on the surface. These infections are very common among the general population, sometimes leading to death. During infections, the bacteria grow in the internal lumen of the stent, forming the so-called "biofilm", normally an aggregation of bacteria with their extracellular products and several inorganic salts (Costerton 2007). This matrix covers the cells, leading to a reduced susceptibility to prophylactic antibiotics (Tenke et al. 2004). Moreover, the development of 
these encrustations can obstruct the device and impair the urinary flow, compromising with patient care and leading to kidney infections, sepsis and shock (Warren et al. 1994).

Temporary prevention from encrustation includes stent replacement at regular intervals, modification of the type or size of catheters, washing the catheter and bladder with acidic, antiseptic or saline solutions (Arshad, Shah and Abbasi 2006). Antibiotics are still orally administered whenever stent is replaced or inserted for preventing infections (Reid 2001).

However all these approaches are mostly ineffective. For this reason stent surface modifications have been proposed to prevent bacterial and inorganic molecule adhesion. Various strategies have been conceived, using silver-coated surfaces (Leung et al. 1992; Multanen et al. 2000), surface modification towards hydrophobicity (Jansen et al. 1993) or functional groups creation with intrinsic antimicrobial activity. Heparin is a good candidate for solving these problems. In previous in vitro and in vivo studies, heparinization of medical devices showed a reduction of microbial colonization (Appelgren et al. 1996; Cauda et al. 2008; Ruggieri et al. 1987). Heparin is a highly sulfated, anionic polysaccharide known for its anti-coagulant and anti-thrombogenic properties (Piper 1946). It has a strong negative electrical charge able to prevent cells adhesion since bacterial' cell membrane surface is also negatively charged. Coating stents with heparin can be practical and low-cost. Over the last three decades several studies, especially in vascular medicine, were indeed reported, showing that this approach is effective (Appelgren, Ransjo, Bindslev et al. 1996; Hildebrandt et al. 1999; Ruggieri, Hanno and Levin 1987).

Another successful approach preventing biofilm formation comprises the use of DiamondLike Carbon (DLC) coatings on the ureteral stent. DLC is a thermodynamically meta-stable state of carbon where diamond-like (sp3-hybridized) and graphite-like (sp2-hybridized) bonding coexist with a large fraction of sp3 bonds. Coatings can be prepared by miscellaneous deposition methods, e.g. ion deposition, sputtering, pulsed laser deposition and plasma-enhanced chemical vapor deposition, using accelerated hydrocarbon ions as film forming particles (Grill 1999). In general, they are characterized by high mechanical hardness and chemical inertness. Depending on the deposition conditions, the properties of DLC films can be adjusted depending on the applications, e.g. allowing enhancement of the wear and corrosion resistance of precision cutting and machining tools. These films are already used as protective coatings on magnetic hard disks and optical glasses. They showed excellent tribological and mechanical properties, corrosion resistance, biocompatibility, and hemocompatibility (Anne Thomson et al. 1991; Roy and Lee 2007; Voevodin and Donley 1996). Recent studies have been focused on their ability to decrease the formation of crystalline bacterial biofilm as well as stent related side effects and discomfort (Laube et al. 2006; Laube et al. 2007).

The evaluation of the in vivo efficacy of both heparin and plasma deposited DLC-coated ureteral stent have been reported. Recent works show the superiority of both coated stents for preventing biofilm adhesion and encrustation compared to uncoated PU catheters (Cauda et al. 2009). 
Despite these recent advances, oral administration of antibiotics (e.g. ciproflaxin) cannot be avoided. Papers in this respect report that bacteria proliferation has been addressed with a local release of antibiotics or antiseptics (Cormio et al. 2001; John et al. 2007; Leung et al. 2001; Raad et al. 1997). Drug-Eluting Stent (DES) has the advantage of maximizing the local tissue levels of therapeutic agents while minimizing systemic toxicity. The problem has been faced with antibiotics incorporation (Gorman and Woolfson 2002) using novel biomimetic and bioactive silicones. For example, with a gentamicin-releasing urethral catheter, encrustation inhibition in a rabbit model has been shown in the short term (Cho et al. 2001). Other authors (Cadieux et al. 2006) reported on a triclosan-loaded ureteral stent implanted in rabbit bladders with bacterial infection. The study showed a significant decrease of urinary tract infection rate. However, a very high control on the delivery kinetics has been not achieved yet.

Another important problem with stents is that they require an additional cytoscopic procedure for their removal. Stents removal may be uncomfortable for the patient, in particular when these are encrusted, therefore requiring hospitalization and anaesthesia. Considering this big concern, the development of time bio-degradable stent materials has become a major keypoint. In principle, bio-adsorbable stents shall be designed to maintain their integrity for a given period of time, and undergo a dissolution process followed by spontaneous expulsion by the patient at the same time.

So far, the bio-degradable stents degrade very fast (typically 48h) or leave fragments removable by lithotripsy and ureteroscopy (Lingeman et al. 2003). Some tests on pigs with degradable poly-L-lactic-L-glycolic acid (PLGA) devices showed fragments embedded in the ureteral walls within cystic sacs, normally leading to fibrosis, inflammation and a large foreign body giant cell reaction (Olweny et al. 2002). These results show that further enhancement on their degradable characteristics is highly required. It is straightforward that the future of ureteral stents will head towards this direction, i.e. to chemically controlled biodegradation, combined to a concomitant release of biologically active molecules on target sites and with minimally invasive surgical procedures. Moreover, highly engineered stents can possibly work as a "scaffolds" for tissue regeneration via cell attachment and proliferation, finally controlling the local inflammation and healing (Zdrahala and Zdrahala 1999).

This chapter focuses in details on the use of PU catheters for endourological applications, providing new insights on the in vivo performances of PU stent. Given to our past expertise, we report on the influence of the PU surface treatments in preventing the encrustation and the formation of bacterial biofilm when implanted into the ureter.

\section{Application}

As an application of PU in biomedical devices, in this paragraph we present our clinical experience with ureteral stents. In particular the focus is driven on the in vivo efficacy of PU stents and their surface modification with heparin or with diamond-like carbon. Parameters 
like biofilm formation, inorganic encrustation extent, stiffness, brittleness or failure of the PU material depending on the indwelling time will be examined. The surface chemistry and morphology characterization of the indwelled stents will also be evaluated according to the surface coating and biofilm formation. The characterization techniques used in this work included Field Emission Scanning Electron Microscopy (FESEM), Energy Dispersive Spectroscopy (EDS), and Infrared (IR) spectroscopy.

\subsection{Experimental part: Patients, stents and characterization methods}

We review here the results collected from 2006 to 2010, concerning the characterization studies on uncoated, heparin- and DLC-coated PU double-J ureteral stents (all provided by Cook Ireland LTD) after indwelling. We enrolled 59 patients (from 45 to 75 years old). 49 patients showed unilateral ureteral obstruction, thus requiring ureteral stenting in the affected ureter. The patients with unilateral obstruction received an heparin-coated, DLCcoated or an uncoated PU stent in the ureter to be treated.

10 patients suffered from bilateral obstruction, therefore the coated and uncoated PU stents were indwelled at the same time in both ureters, respectively. Each patient with bilateral obstruction received randomly both the coated stent (with heparin or with a diamond-like carbon coating) in one ureter, and the uncoated one, thus the pure PU stent, in the other ureter.

Stents indwelling was also studied for different periods of time. The stent types and indwelling times are reported in Table 1.

\begin{tabular}{|c|c|c|c|}
\hline $\begin{array}{c}\text { Number of } \\
\text { stents }\end{array}$ & Coating & Indwelling time & $\begin{array}{c}\text { Type of } \\
\text { indwelling }\end{array}$ \\
\hline \multicolumn{5}{|c|}{} \\
\hline 14 & Heparin & $1-3$ months & Unilateral \\
\hline 9 & Heparin & $>3$ months & Unilateral \\
\hline \multicolumn{4}{|c|}{} \\
\hline 19 & None ${ }^{\mathrm{a}}$ & $1-3$ months & Unilateral \\
\hline 3 & None & $>3$ months & Unilateral \\
\hline \multicolumn{4}{|c|}{} \\
\hline 4 & DLC & 1 month & Unilateral \\
\hline $5^{\mathrm{b}}$ & None & 1 month & Bilateral \\
\hline $5^{\mathrm{b}}$ & Heparin & 1 month & Bilateral \\
\hline \multicolumn{5}{|l|}{} \\
\hline $5^{\mathrm{b}}$ & None & 1 month & Bilateral \\
\hline $5^{\mathrm{b}}$ & DLC & 1 month & Bilateral \\
\hline
\end{tabular}

a None indicates that the stent surface is of pure PU.

${ }^{\mathrm{b}}$ These stents were implanted bilaterally, thus inserting both the uncoated and the coated stents into both ureters respectively of the same patient.

Table 1. Stents types and indwelling periods of the PU, heparin-coated and diamond-like carbon coated PU stents. 
The criteria used for patient selection for indwelling time of 1 month were mainly postendoscopic stone treatment, ureteropelvic junction (UPJ) obstruction (awaiting surgery). In the long term indwelling (thus 3 or more months) stenting was performed in case of hydronephrosis due to extrinsic compression in patients with multi-cystic disease (no surgical indications) and UPJ obstruction after failure of endoscopic and surgical treatments (patient refused re-intervention). Pregnant women, patients with dermatitis or a burn over the insertion site were excluded. All patients enrolled in this study gave their informed consent.

In all cases, double-J stents were placed using a retrograde uretero-pielography approach during cystoscopy, as suggested by the stent producer, to evaluate the excretory system.

Ciprofloxacin (500 mg twice a day) was administered for prophylaxis for the first 4 days after the procedure. Any occurrence of technical problems and violations of aseptic conditions during the procedures were recorded. The antibiotic therapy administrations, other therapeutic interventions administered during the period of indwelling, the presence of fever, infections or urinary symptoms were also recorded. After the procedure, the follow-up check included urine analysis and culture on day 15 and afterwards every three months. In addition, a complete blood count, serum creatinine levels, and ultrasonography were performed on day 30, and every 3 months thereafter. All patients received instructions to present themselves at the institution in the event of experiencing side pain, fever, dysuria, hematuria, or vomiting.

The stents were removed after different times (see Table 1) during cystoscopy. Characterization of the stents after the indwelling period was carried out using morphological and compositional analysis and the results obtained were compared with the reference stent before use. In particular they were cut both perpendicularly and parallel to the stent axis in order to obtain cross sections or plan views of the inner and outer surfaces (Figure 1). The samples were then characterized by three different techniques:

a. FESEM (JEOL JSM 6500F) for the morphological characterization of the stent surface and the formed encrustations;

b. EDS (INCA) to collect data about the chemical composition of the stent material and the deposited encrustation at the inner and outer surface of the samples;

c. IR spectroscopy on Attenuated Total Reflectance mode (ATR, Bruker Equinox 55) for the identification of the chemical compounds deposited on the inner and outer surface of the samples.

Measurements (a) and (b) were carried out at the same time. Since the stent are made of a polymeric material (polyurethane), i.e. constituted by carbon, oxygen, hydrogen, and nitrogen, these elements are excluded from the elemental analysis on the encrustation. Moreover, the specimen is fixed to the sample holder for the FESEM and EDS characterizations by a carbon sticker, the composition of which also interferes with the elemental analysis of the stent itself. For these reasons, the detection of bacterial biofilm is not possible with the EDS technique and therefore IR spectroscopy is required. 
IR spectroscopy was carried out directly on the inner and outer surfaces of the cut stent in Attenuated Total Reflectance (ATR) mode by means of a diamond immersion probe (as shown in Figure 1, scheme a).

All the described measurements were also performed on reference stents without in-vivo indwelling.

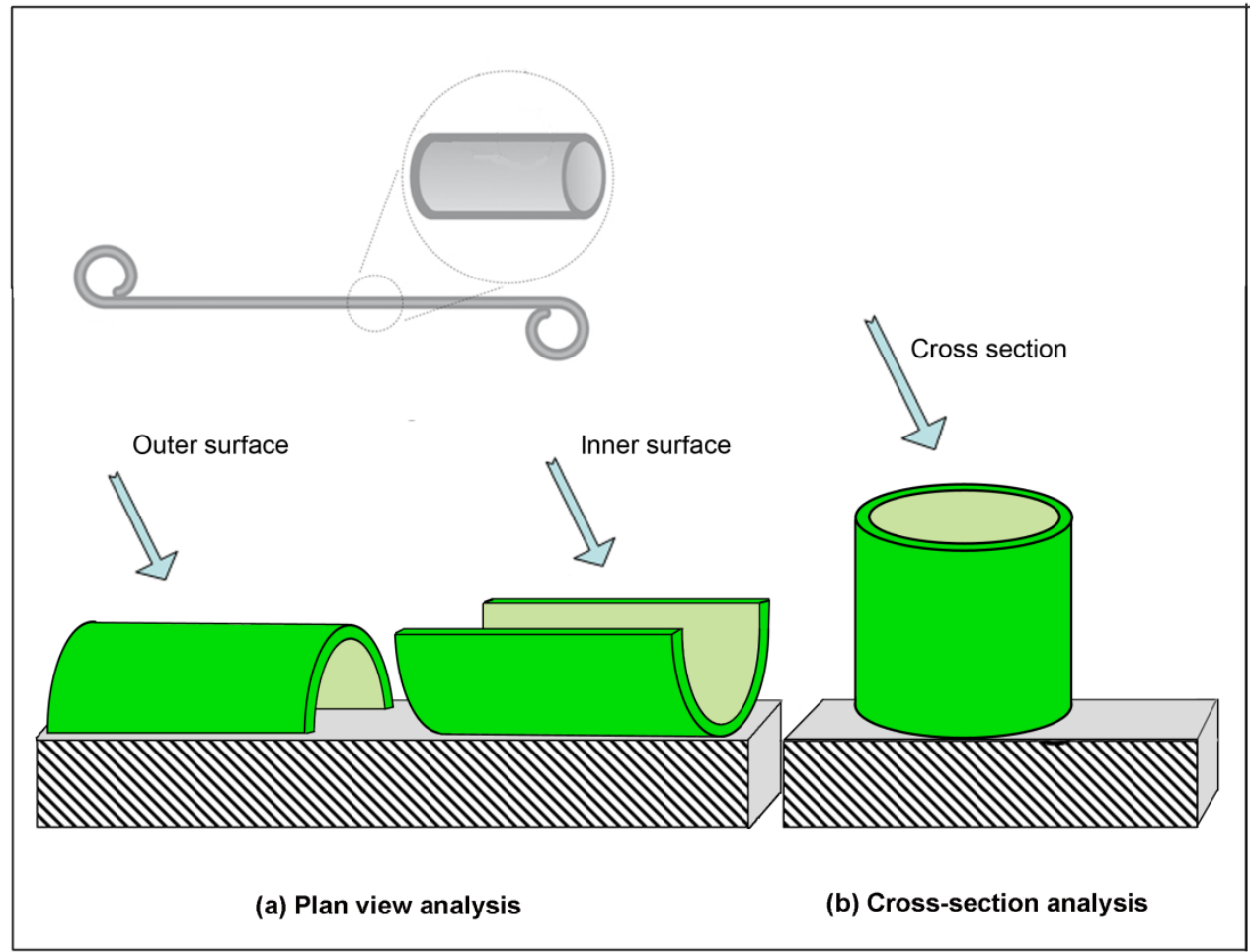

Figure 1. Scheme of the analyzed surfaces for the polyurethane ureteral stents for the characterization with FESEM and IR spectroscopy IR. (a) For the plan view analysis, a cut along the stent axis was carried out for characterizing the outer (left) and inner (right) surface; (b) Cross-sections were obtained by cutting the stent perpendicular to its axis.

\subsection{Clinical results}

No technical problems or violations of aseptic conditions during endoscopic procedures were recorded. In all cases retrograde uretero-pielography, performed at the start of the procedure, showed unilateral or bilateral ureteral obstruction with various degrees of excretory system dilatation. 
None of the patients reported fever, side pain or voiding symptoms during the period of study. Urine culture was negative in all cases. In three patients, groups frequency/urgency symptoms were recorded. Until stents removal, these patients were successfully treated with antimuscarinics. Follow-up examination revealed no diferences in blood count, serum creatinine and ultrasonographic features of kidney and ureter with respect to the baseline values. During indwelling, all the stents were well tolerated.

Stents were removed without technical difficulties in all cases. No technical problems occurred during the endoscopic procedures on ten patients showing chronic unilateral obstruction. In these cases, uretero-pielography showed ureteral obstruction with severe excretory system dilatation.

\subsection{Characterization results on starting stents surfaces}

The starting stent surfaces were analyzed prior to indwelling, in order to evaluate the differences between the pure PU surface, the heparin- and DLC-coatings.

To understand the performances of both coatings in preventing bacterial adhesion and encrustation with respect to the PU material, the stents were also characterized after different indwelling times (see Table 1 for details). These results will be discussed in the next paragraphs.

Here we report on the results from the different characterization techniques concerning the stents before patient's indwelling (hereafter "reference-stents"). It is intended that all the results and comments presented in the Paragraph 2.4 are based on the comparison with these reference stents.

Figure 2 shows the surface morphology (measured by FESEM) of the PU (uncoated), heparin-coated and DLC-coated stents. The internal and external surfaces of the PU stent (Figure 2.a and 2.b) presented several irregularities, attributed to the polyurethane particles (of about $0,5-1 \mu \mathrm{m}$ ) or undispersed barium sulfate particles, used to impart radiopacity to the stent. The elemental analysis by means of EDS showed no additional results, since carbon, oxygen and nitrogen are excluded due to the reasons mentioned in the Paragraph 2.1. For this reason the results of the EDS analysis are not shown.

At the edge of heparin-coated reference-stent it was possible to observe the smooth heparin layer on the polyurethane substrate (Figure 2.d), with a thickness of about $5 \mu \mathrm{m}$.

The EDS shows the presence of sulphur, an element present in the heparin chemical formula together with $\mathrm{C}, \mathrm{O}$ and $\mathrm{N}$. Barium was present in the black paint line, used as fluoroscopic marker, at the outer surface of the catheter.

Figure 2.e shows the external surface, close to a lateral drainage hole, of the DLC-coated reference-stent. At the internal surface of this stent (Figure 2.f) several grains and thin cracks were observed, possibly attributed to the carbon coating. The elemental analysis on DLCcoated stent surface detected carbon, oxygen and nitrogen, attributed to PU. 

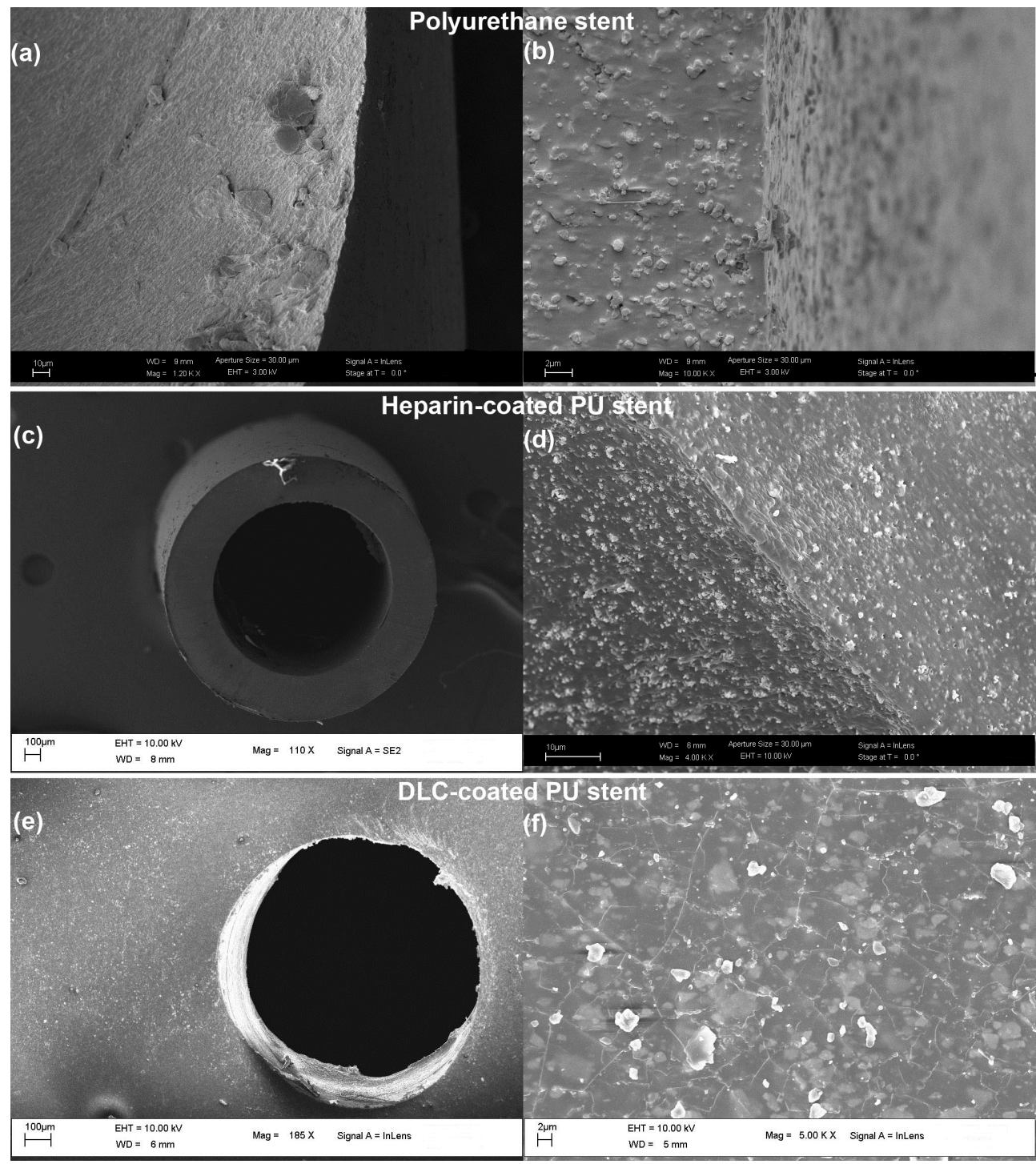

Figure 2. FESEM results of the stents surfaces of PU, Heparin-coated PU and carbon-coated PU.

The IR spectra of the reference-stents are shown in Figure 3 and were recorded at the internal surface, showing the functional groups of PU, heparin and DLC. 


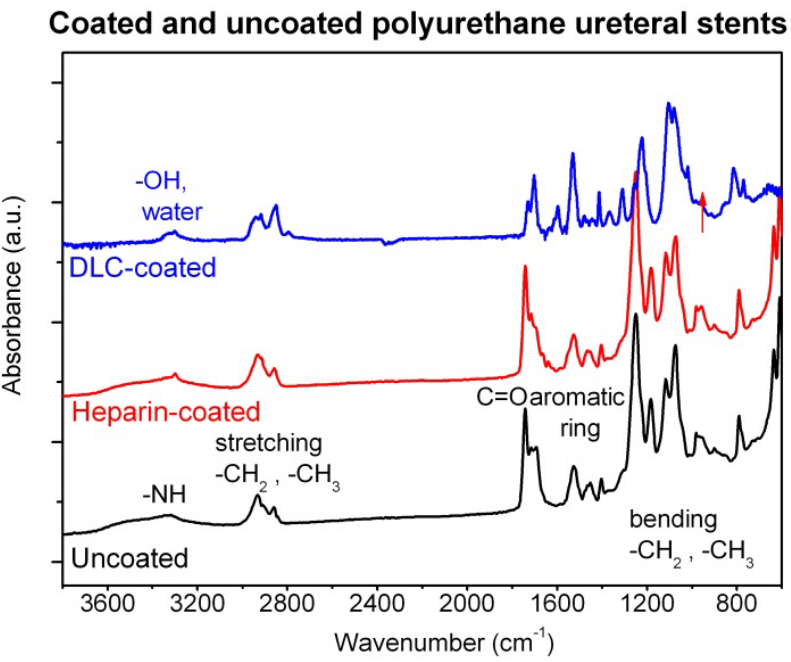

Figure 3. IR of the stents surface: comparison between PU stents without coating and with heparin and diamond-like carbon coatings.

The PU spectrum (in black) in the $3800-1200 \mathrm{~cm}^{-1}$ region reflected the vibration modes of its functional groups. Hydroxyl groups $(-\mathrm{OH})$ and physisorbed hydration water were responsible for the bands from 3700 to $3100 \mathrm{~cm}^{-1}$. The stretching vibration of the $-\mathrm{NH}$ group was associated to the band at $3300 \mathrm{~cm}^{-1}$, while peaks at 2900 and $2860 \mathrm{~cm}^{-1}$ are the stretching vibrations of alkyl $-\mathrm{CH}_{2}$ and $-\mathrm{CH}_{3}$ groups. The peak at $1690 \mathrm{~cm}^{-1}$ represents another vibration mode (bending) of clustered water. The band at $1740 \mathrm{~cm}^{-1}$ indicated the carboxyl group $\mathrm{C}=\mathrm{O}$ vibration mode, at $1450 \mathrm{~cm}^{-1}$ the mode of the aromatic ring $\left(\mathrm{C}_{6} \mathrm{H}_{6}\right)$ and at 1400 $\mathrm{cm}^{-1}$ the bending modes of alkyl $-\mathrm{CH}_{2}$ and $-\mathrm{CH}_{3}$ groups. In the spectral zone below $1200 \mathrm{~cm}^{-}$ ${ }^{1}$ only collective vibrations of the single bonds were observed since the bands in this range are typical of the polymer chain and constitute its "fingerprint".

In the DLC-coated stent spectrum (in blue), no significant differences were appreciable with respect to the previous PU spectrum, however several changes in the peak intensities were observed. In particular, the band from 3400 to $3250 \mathrm{~cm}^{-1}$, representing water, $-\mathrm{OH}$ groups and amine group $(-\mathrm{NH})$ were more intense. A similar increase was observed for to the bending peak of water at $1690 \mathrm{~cm}^{-1}$, concluding that the DLC-coated stent surface was more hydrophilic than the untreated polyurethane catheter. Stretching peaks at 2940 and $2850 \mathrm{~cm}^{-}$ 1 , representing alkyl $-\mathrm{CH}_{2}$ and $-\mathrm{CH}_{3}$ groups, also showed an increased intensity, due to the plasma treatment implanting hydrocarbon ions. For the same reason, similar changes in intensity were observed at $1400 \mathrm{~cm}^{-1}$ for the peak related to $-\mathrm{CH}_{2}$ and $-\mathrm{CH}_{3}$ bending vibrations and an additional peak at $1597 \mathrm{~cm}^{-1}$ attributed to the $\mathrm{C}=\mathrm{C}$ group. The IR light beam penetrated under the thin DLC-modified surface and also detected the polyurethane surface. For example, the aromatic ring belonging to PU was also slightly observed in the range between 1430 and $1290 \mathrm{~cm}^{-1}$. 
The spectrum of the heparin-coated PU surface (in red) shows some new features with respect to the PU reference-stent (in black). In particular, the broad band from 3700 to 3100 $\mathrm{cm}^{-1}$, representing water and -OH groups, showed a lower intensity. A similar decrease was observed for the bending peak of water at $1690 \mathrm{~cm}^{-1}$. It was than concluded that the heparin coated stent surface showed lower hydration than the uncoated one. In contrast, stretching peaks at $3300 \mathrm{~cm}^{-1}$, belonging to $-\mathrm{NH}$ groups, and peaks at 2900 and $2860 \mathrm{~cm}^{-1}$, representing alkyl $-\mathrm{CH}_{2}$ and $-\mathrm{CH}_{3}$ groups, increased, since both functional groups were also present in the heparin chemical formula. For the same reason, similar changes in intensity were detected at $1400 \mathrm{~cm}^{-1}$ for the peak related to $-\mathrm{CH}_{2}$ and $-\mathrm{CH}_{3}$ bending vibrations. Additional peaks appeared in the range from 1650 to $1600 \mathrm{~cm}^{-1}$, due to the presence of carboxylate $(-\mathrm{COOH})$ and sulphate $\left(-\mathrm{SO}_{4}\right)$ groups belonging to heparin. The other peaks of the red spectrum are no longer discussed, since they belonged to the PU substrate.

\subsection{Characterization results on the indwelled stents}

In the following sections, the results on the indwelled stents are reported and divided according to the indwelling time (from 1 to 3 months, more than 3 months) and the adopted approach (unilateral or bilateral indwelling). In addition, some example will be given in order to show how the patient pathology, such as recidivist calculosis, would affect the stent surface.

\subsubsection{Stents indwelled unilaterally for 1 - 3 months}

In this section we will examine the surface characterization of stents indwelled unilaterally and for a period ranging from 1 to 3 months. We have examined (see also Table 1):

i. 19 PU stents;

ii. 14 heparin-coated stents;

iii. 4 DLC-coated stents.

The samples were analyzed by means of the three techniques described above. The characterization aimed to evaluate the presence of bacterial biofilm and inorganic encrustations, such as calcium oxalate $\left(\mathrm{CaC}_{2} \mathrm{O}_{4}\right)$, sodium chloride $(\mathrm{NaCl})$, brushite $\left(\mathrm{CaHPO}_{4} \bullet 2 \mathrm{H}_{2} \mathrm{O}\right)$ and other salts, such as silica $\left(\mathrm{SiO}_{2}\right)$ and compounds of magnesium $(\mathrm{Mg})$ and potassium (K). The obtained data were used to evaluate the behavior of PU ureteral stent in vivo according to the indwelling time and the surface treatment.

Figure 4 shows the comparison between the surfaces of PU, heparin-coated and DLC-coated stents, indwelled unilaterally into three different patients. They were all indwelled into the patient's ureter after the stone removal from the kidney by endoscopic lithotripsy with holmium laser. In the cases of both heparin-coated and DLC-coated stents almost clean and encrustation-free surfaces were observed (Figures 4.e-4.l). In contrast, higher levels of encrustation were detected at both the inner and outer surfaces of the PU stent (Figures 4.a-4.d).

The elements found at both inner and outer stent surfaces by means of Energy Dispersive Spectroscopy (EDS) are reported in Table 2. Some inorganic salts were detected at all the stent surfaces, such as sodium chloride $(\mathrm{NaCl}$, evidenced by the presence of both $\mathrm{Na}$ and $\mathrm{Cl}$, Table 
2). In addition, oxides of calcium (evidenced only from the presence of $\mathrm{Ca}$, whereas oxygen and carbon were both not taken into account by EDS analysis), silica (revealed by Si element), phosphorous $(\mathrm{P})$ and potassium $(\mathrm{K})$ were collected. In the case of the heparin-coated stent, the sulphur (S) element present at both inner and outer surfaces clearly derived from the heparin layer.
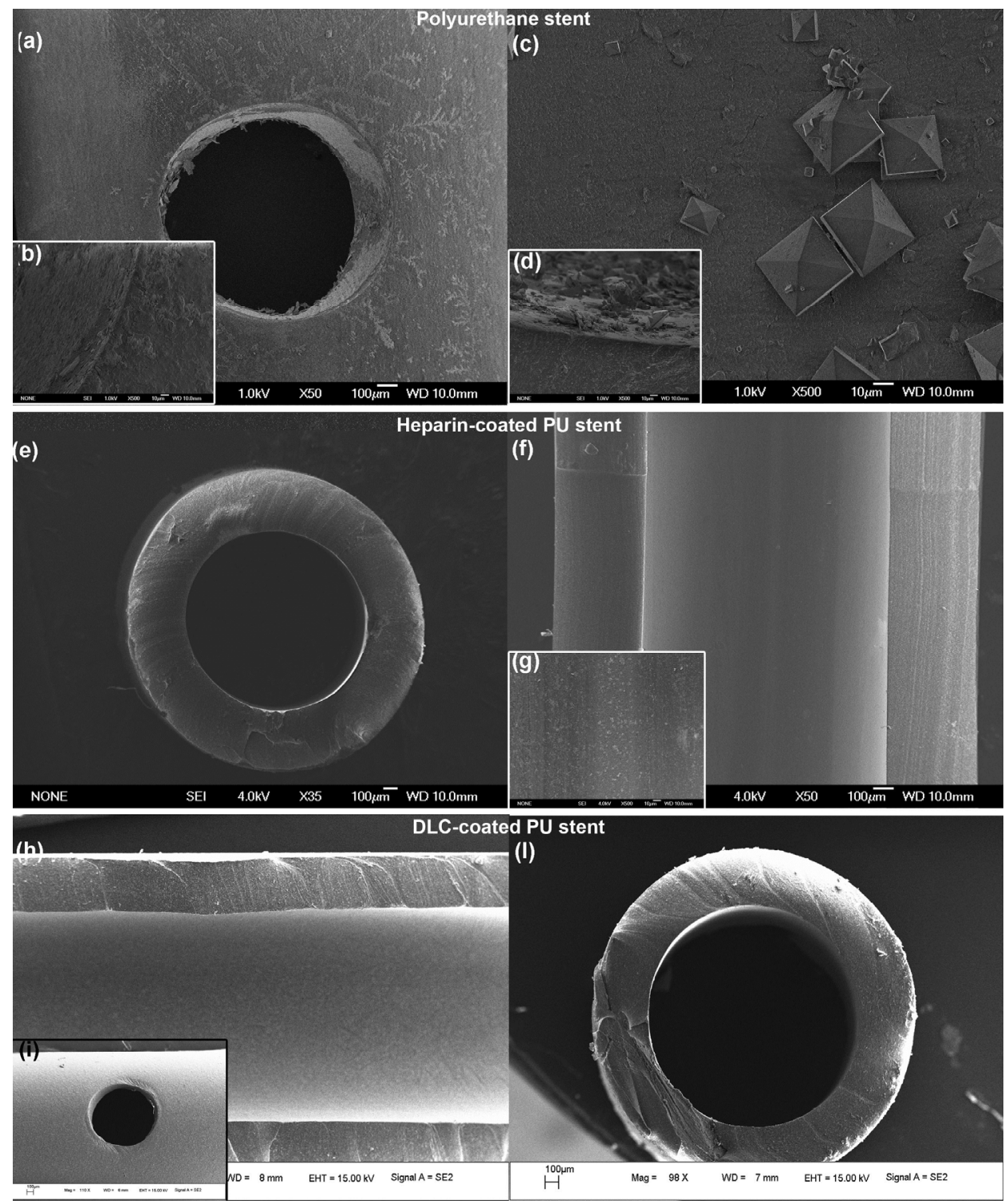

Figure 4. FESEM results of PU, heparin-coated and DLC-coated polyurethane stents surfaces after unilateral indwelling for a period ranging from 1 to 3 months. 


\begin{tabular}{|c|c|c|c|c|c|c|c|c|c|c|c|}
\hline \multicolumn{4}{|c|}{ PU stent } & \multicolumn{4}{|c|}{ Heparin-coated stent } & \multicolumn{4}{|c|}{ DLC-coated stent } \\
\hline \multicolumn{2}{|c|}{ Inner Surface } & \multicolumn{2}{|c|}{ Outer Surface } & \multicolumn{2}{|c|}{ Inner Surface } & \multicolumn{2}{|c|}{ Outer Surface } & \multicolumn{2}{|c|}{ Inner Surface } & \multicolumn{2}{|c|}{ Outer Surface } \\
\hline Element & $\begin{array}{c}\text { Atom } \\
\%\end{array}$ & Element & $\begin{array}{c}\text { Atom } \\
\%\end{array}$ & Element & $\begin{array}{c}\text { Atom } \\
\%\end{array}$ & Element & $\begin{array}{c}\text { Atom } \\
\%\end{array}$ & Element & $\begin{array}{c}\text { Atom } \\
\%\end{array}$ & Element & $\begin{array}{c}\text { Atom } \\
\%\end{array}$ \\
\hline $\mathrm{Na} K$ & 29.17 & $\mathrm{Na} \mathrm{K}$ & 37.71 & $\mathrm{Na} K$ & 22.79 & Na K & 0.00 & $\mathrm{Na} K$ & 0.00 & $\mathrm{Na} K$ & 10.70 \\
\hline $\mathrm{Mg} \mathrm{K}$ & 0.00 & $\mathrm{Mg} \mathrm{K}$ & 0.00 & $\operatorname{Mg~K}$ & 0.0 & $\mathrm{Mg} \mathrm{K}$ & 0.00 & $\operatorname{Mg~K}$ & 0.00 & $\operatorname{Mg~K}$ & 0.00 \\
\hline Si K & 3.55 & Si K & 0.00 & Si K & 0.00 & $\mathrm{SiK}$ & 0.00 & Si K & 0.00 & Si K & 0.62 \\
\hline P K & 2.14 & P K & 2.48 & $\mathrm{PK}$ & 0.00 & P K & 0.00 & P K & 0.00 & P K & 0.00 \\
\hline S K & 1.89 & S K & 0.00 & S K & 38.40 & S K & 61.01 & S K & 0.00 & S K & 0.00 \\
\hline $\mathrm{Cl} \mathrm{K}$ & 20.45 & $\mathrm{Cl} \mathrm{K}$ & 38.09 & $\mathrm{Cl} \mathrm{K}$ & 10.07 & $\mathrm{Cl} \mathrm{K}$ & 0.00 & $\mathrm{Cl} \mathrm{K}$ & $\begin{array}{c}100.0 \\
0\end{array}$ & $\mathrm{Cl} \mathrm{K}$ & 88.78 \\
\hline K K & 2.46 & K K & 2.06 & K K & 0.00 & K K & 0.00 & K K & 0.00 & K K & 0.00 \\
\hline Ca K & 34.99 & Ca K & 0.00 & Ca K & 2.61 & Ca K & 0.00 & Ca K & 0.00 & $\mathrm{Ca} \mathrm{K}$ & 0.00 \\
\hline $\mathrm{Bi} \mathrm{K}$ & 5.35 & $\mathrm{Bi} \mathrm{K}$ & 19.66 & Ba L & 26.13 & Ba L & 38.99 & Ba L & 0.00 & Ba L & 0.00 \\
\hline
\end{tabular}

Table 2. EDS analysis on PU, heparin-coated and DLC-coated stent surfaces after 1-3 months of unilateral indwelling.

IR spectroscopy (here only the spectra carried out at the internal surfaces are shown, see Figure 5) confirmed the previous findings (a higher content of water was observed in the case of DLC-coated stent, blue spectrum). It was therefore concluded that the stent surfaces were clean and the bacterial biofilm was not detected.

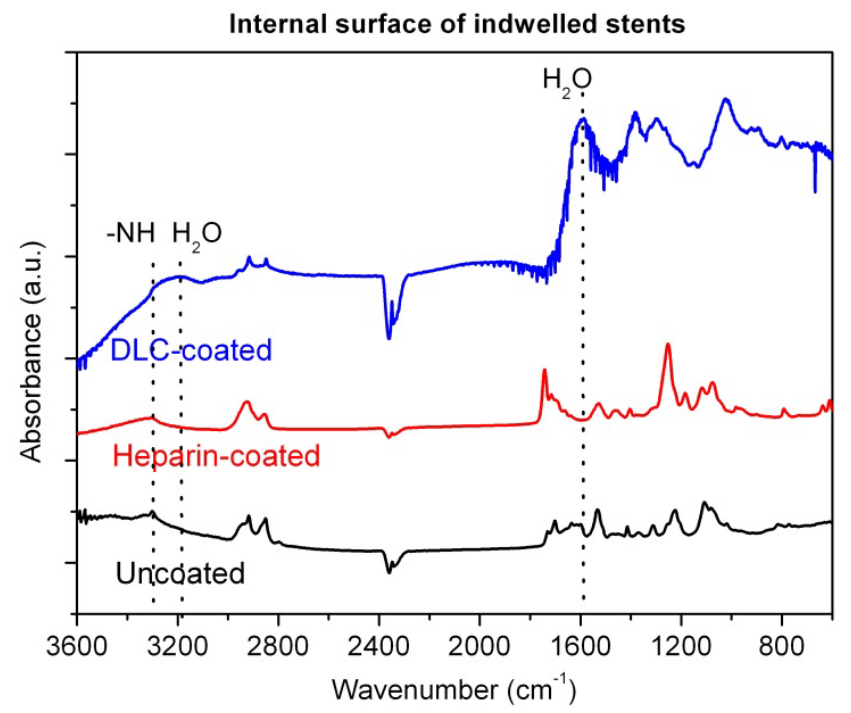

Figure 5. IR of the internal stent surfaces.

By combining the results of the three characterization techniques, the following considerations can be drawn: (i) the inner surface of the stents, independently from the surface treatment, was more encrusted than the outer one; (ii) the PU stent showed higher level of inorganic encrustation with respect to both surface-modified stents. 
To see how the patient's pathology and conditions affected the ureteral stents, in Figure 6 we compare the surfaces of three PU, heparin-coated and DLC-coated stents respectively, indwelled into stone-former patients. All the catheter surfaces were heavily encrusted; however lower level of depositions were observed at both the coated stent surfaces (Figures 6.d-6.i) with respect to the PU stent (Figures 6.a-6.c).
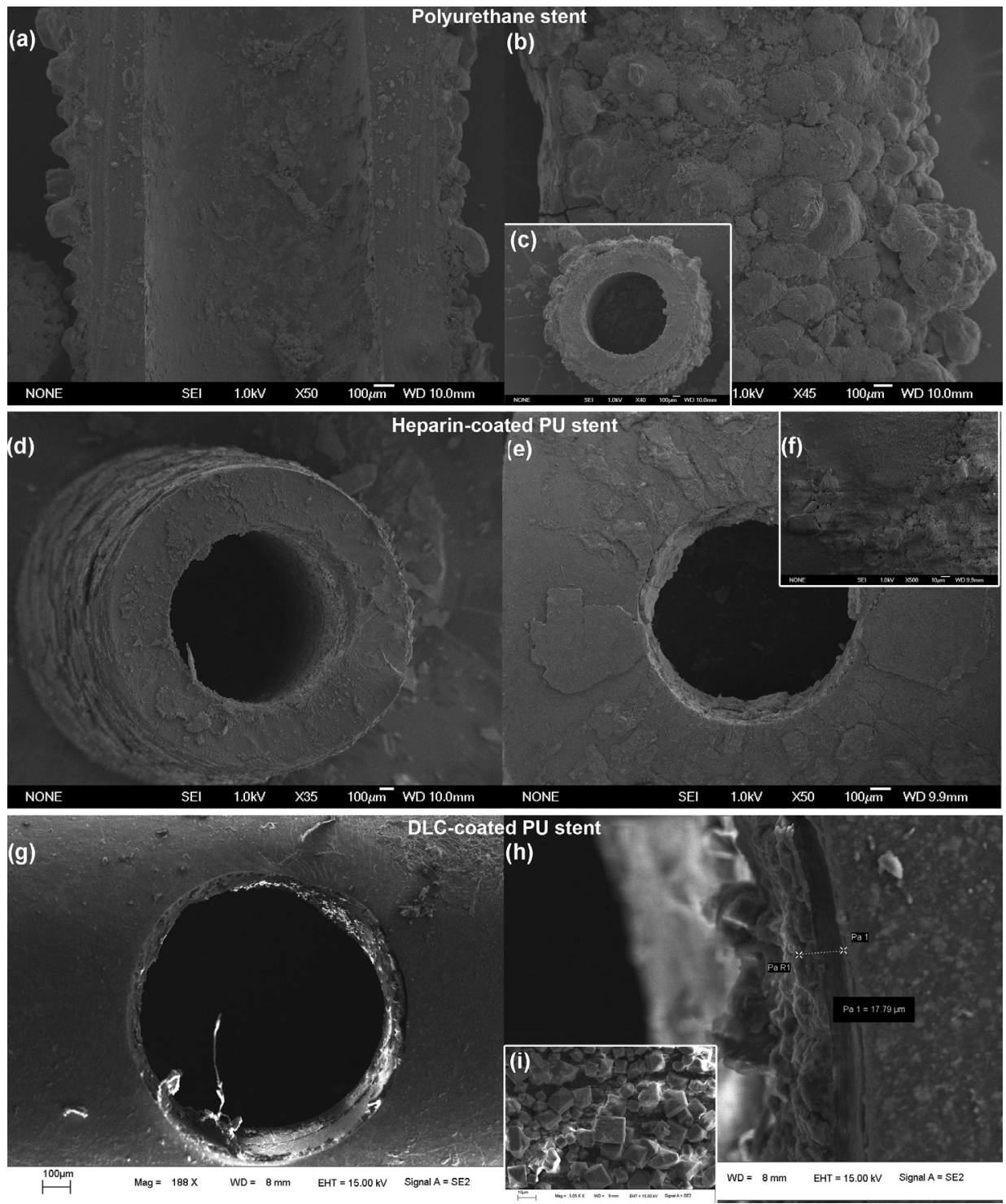

Figure 6. FESEM images of PU, heparin-coated and DLC-coated stents after indwelling of 1-3 months into stone-forming patients. 
The encrustation of the three stents was mainly composed of calcium oxalate, as clearly detected by the IR spectroscopy (Figure 7) and the EDS analysis (here not shown). In particular, IR spectrum of the oxalate crystals was very well defined, with the characteristic peaks at 1706 and $1313 \mathrm{~cm}^{-1}$ representing the vibration modes of $\mathrm{C}=\mathrm{O}$ and $\mathrm{C}-\mathrm{O}$ groups, respectively. These spectra showed the high purity of the isolated bio-mineral on the stent surfaces. In addition, the vibration modes of the polymeric substrate (heparin, DLC and polyurethane) were no longer recognizable. One can then conclude that the encrustation was thicker than the depth of the analysis (about $1 \mu \mathrm{m}$ using the Attenuated Total Reflection (ATR) detection mode).

These findings do not allow to conclude which stent is more or less encrusted with respect to the surface treatment. Indeed, in stone former patients with recidivist calculosis, whatever stent is applied, the urologist has to plan frequent stent exchange (the suggested indwelling time by the producer is one month indeed), due to the ease of stent encrustation.

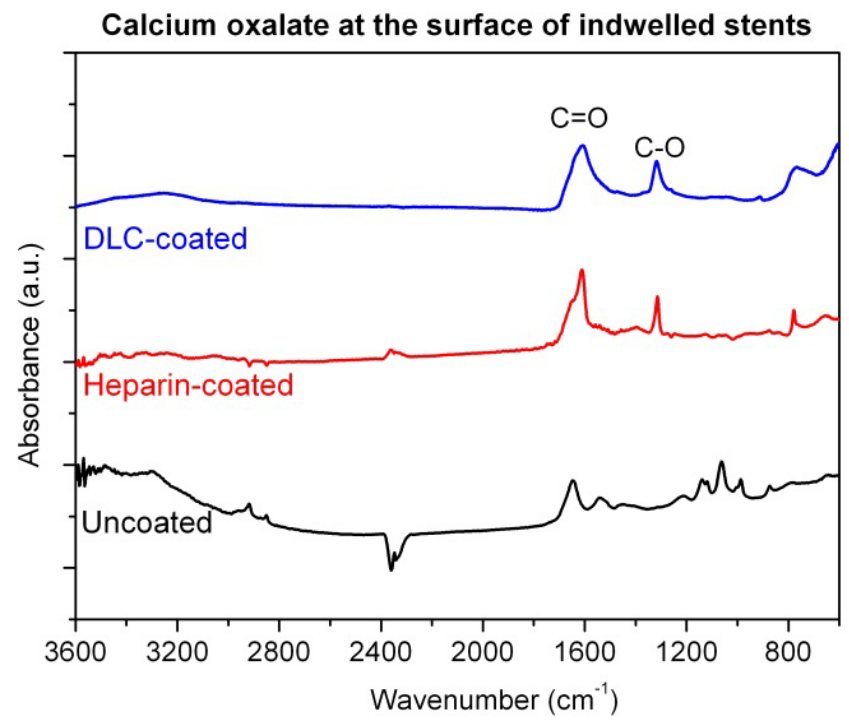

Figure 7. IR spectra of the three stents surfaces, also depicted in Figure 6, clearly showing the vibration modes of calcium oxalate.

\subsubsection{Stents unilaterally indwelled longer than 3 months}

In this paragraph we present the results obtained from the surface characterization of both heparin-coated and unmodified PU stents, indwelled longer than three months. This indwelling time actually exceed the recommendation of the stent producer, and the results are therefore quite interesting. All these patients refused the stent substitution after 3 months, thus the stents were substituted or definitely removed once the consent of patient was given. Again, the stent study has to be divided according to the patient's pathology, that is, stone-former patient or not. 
The first example shows the comparison between PU and heparin-coated stents indwelled unilaterally into non-stone former patients after calculus removal by lithotripsy.

Despite the long indwelling time and the producer recommendation, both stents were quite free from encrustation (Figure 8 shows FESEM characterization). The encrustation thickness was measured $2.5 \mu \mathrm{m}$ at the PU stent, whereas it was not enough compact to form a layer on the heparin-coated surfaces. The results obtained by EDS and IR spectroscopy confirmed the absence of bacterial biofilm on both stent surfaces. In addition, the PU surface showed a higher percentage of sodium chloride and silica with respect to the heparin-coated one. From these findings, one can conclude that the encrustation levels of the surface-treated stent were lower than the PU one.
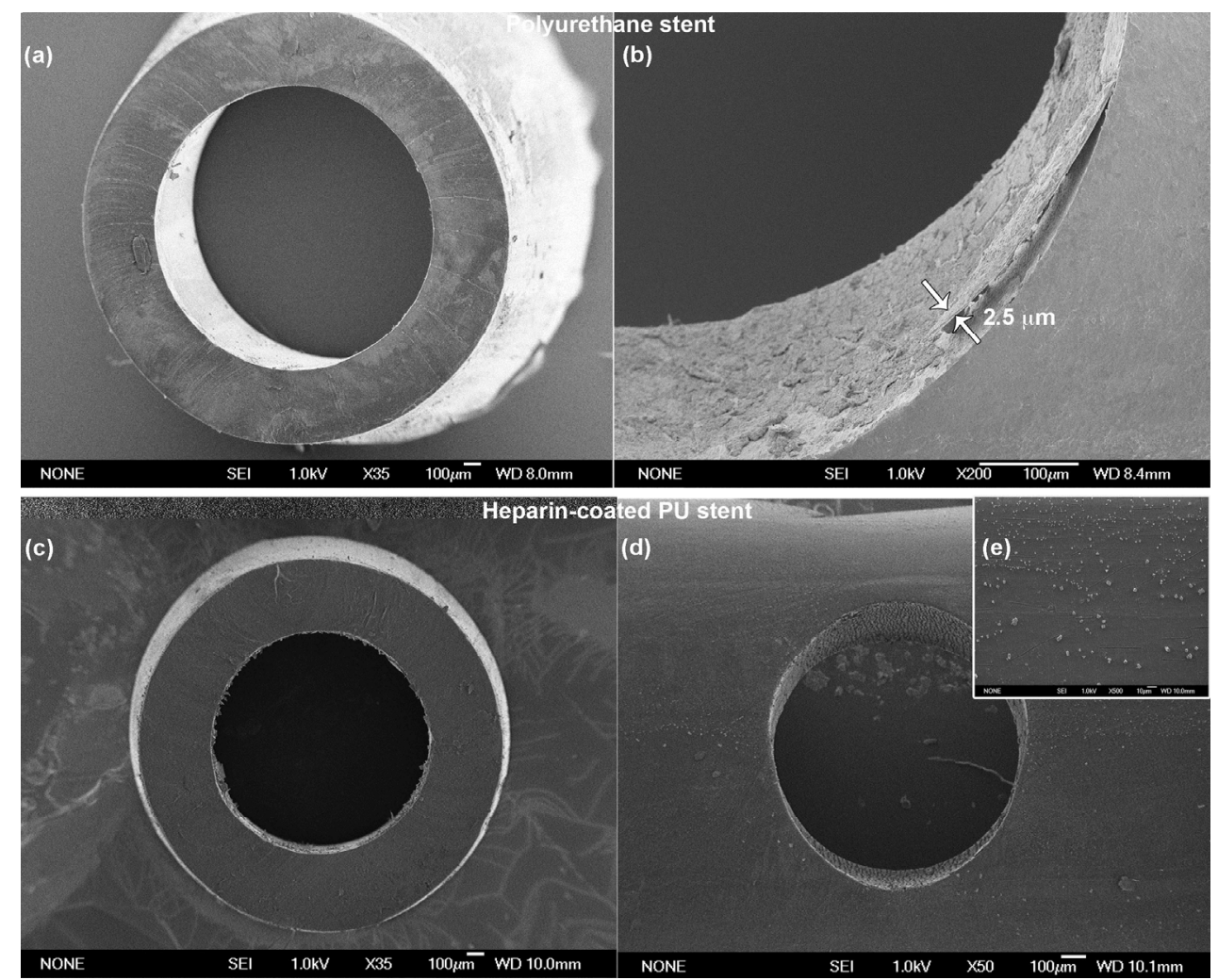

Figure 8. Surface morphology of PU and heparin-coated stents inserted unilaterally for more than 3 months.

The second example referred to the stents indwelled into stone-former patients for longterm periods (more than 3 months). 
In contrast to the previous results, the heparin-coated stent showed higher degree of encrustations at both inner and outer surfaces with respect to the PU stent (Figure 9.a, b, c). In particular, needle-like crystals were observed a higher magnification at the internal stent surface (Figure 9.e and f). This morphology corresponded to the calcium oxalate crystals, and was confirmed by both EDS spectroscopy (due to the presence of calcium in high percentages in Table 3), and IR spectroscopy (Figure 10.b). Indeed both spectra collected at the inner and outer surfaces indicated a thick layer of pure calcium oxalate.
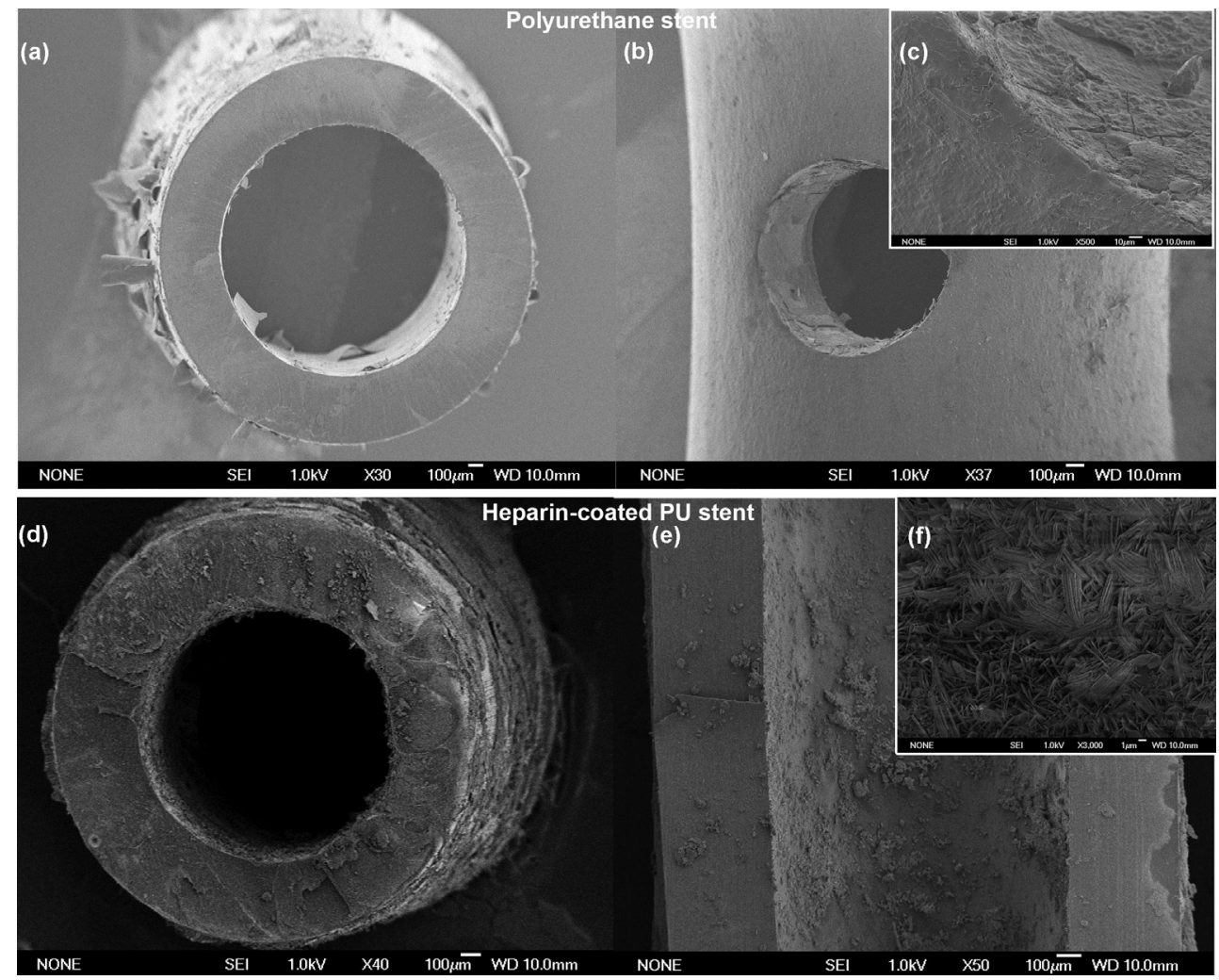

Figure 9. FESEM images of PU and heparin-coated stents indwelled unilaterally for more than 3 months in stone former patients.

In this example no general conclusion can be drawn concerning the comparison of the two stents, since the surface-modified stent and PU one were indwelled into two different patients, although both stone-formers. 


\begin{tabular}{|c|c|c|c|c|c|c|c|}
\hline \multicolumn{4}{|c|}{ PU stent } & \multicolumn{4}{|c|}{ Heparin-coated stent } \\
\hline \multicolumn{2}{|c|}{ Inner Surface } & \multicolumn{2}{|c|}{ Outer Surface } & \multicolumn{2}{|c|}{ Inner Surface } & \multicolumn{2}{|c|}{ Outer Surface } \\
\hline Element & Atom $\%$ & Element & Atom $\%$ & Element & Atom $\%$ & Element & Atom $\%$ \\
\hline $\mathrm{NaK}$ & 34.75 & $\mathrm{NaK}$ & 0.00 & $\mathrm{NaK}$ & 10.14 & $\mathrm{NaK}$ & 0.00 \\
\hline $\mathrm{Mg} \mathrm{K}$ & 0.00 & $\mathrm{Mg} \mathrm{K}$ & 0.00 & $\mathrm{Mg} \mathrm{K}$ & 0.00 & $\mathrm{Mg} \mathrm{K}$ & 0.00 \\
\hline Si K & 18.65 & Si K & 37.77 & Si K & 0.00 & Si K & 0.00 \\
\hline S K & 4.39 & S K & 0.00 & P K & 0.00 & P K & 2.56 \\
\hline $\mathrm{Cl} \mathrm{K}$ & 32.53 & $\mathrm{Cl} \mathrm{K}$ & 37.93 & S K & 24.46 & S K & 0.00 \\
\hline K K & 0.00 & K K & 0.00 & $\mathrm{Cl} \mathrm{K}$ & 3.42 & $\mathrm{Cl} \mathrm{K}$ & 0.00 \\
\hline Ca K & 0.00 & Ca K & 0.00 & K K & 0.00 & K K & 0.00 \\
\hline $\mathrm{Br} \mathrm{L}$ & 0.00 & Br L & 0.00 & Ca K & 43.82 & Ca K & 97.44 \\
\hline $\mathrm{Bi} \mathrm{M}$ & 9.69 & $\mathrm{Bi} \mathrm{M}$ & 0.00 & Ba L & 18.17 & $\mathrm{Ba}$ L & 0.00 \\
\hline
\end{tabular}

Table 3. Results of the EDS analysis carried out at both the inner and outer surfaces of PU and heparincoated stents after prolonged unilateral indwelling into stone-former patients.

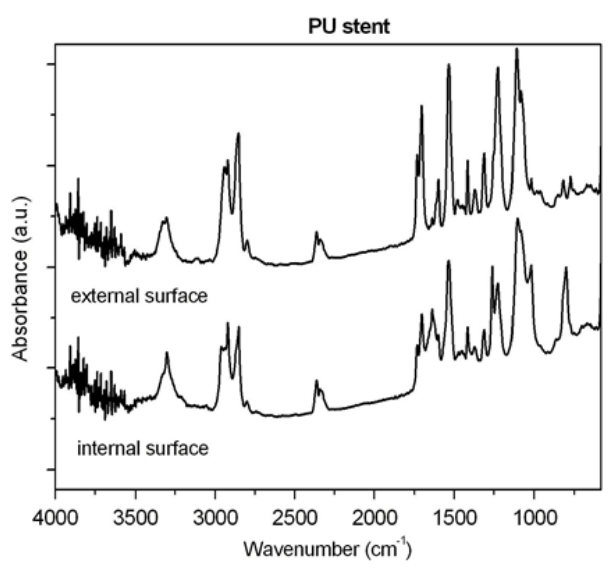

(a)

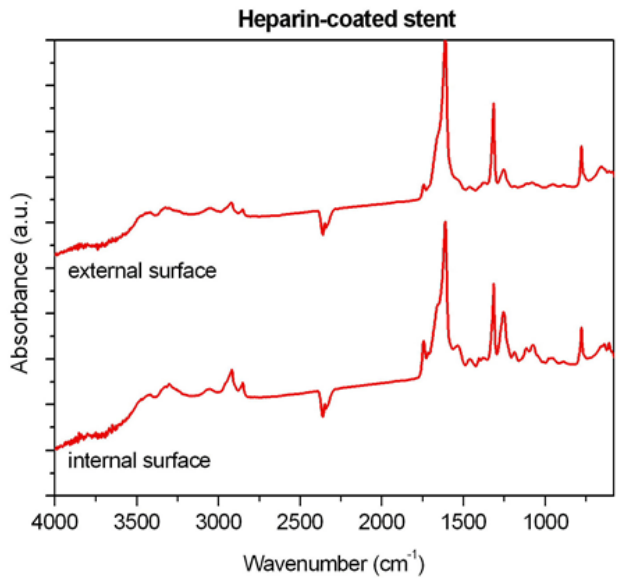

(b)

Figure 10. IR spectroscopy of the internal and external surfaces of (a) PU stent and (b) heparin-coated stent, unilaterally indwelled into stone-former patient for a period longer than 3 months.

\subsubsection{Stents bilaterally indwelled for 1 month}

The bilateral indwelling is the ideal condition to compare the effectiveness of the surface treatment in preventing encrustation, since both stents are exposed to the same patient's conditions.

Here we report on two examples of surface-modified and PU stents, bilaterally indwelled for one month into a non-stone former patient and, in a second case, into a stone-former one.

In the first example, shown in Figure 11 by FESEM, heparin-coated and PU untreated stents were indwelled bilaterally after calculus removal by lithotripsy with holmium laser. Both the treated and untreated surfaces showed low levels of encrustation. The EDS and IR 
spectroscopic characterizations (not shown here) revealed phosphorous, potassium and sodium chloride salts at both stents surfaces, with higher percentages of bacterial biofilm at the inner surface of the PU stent.

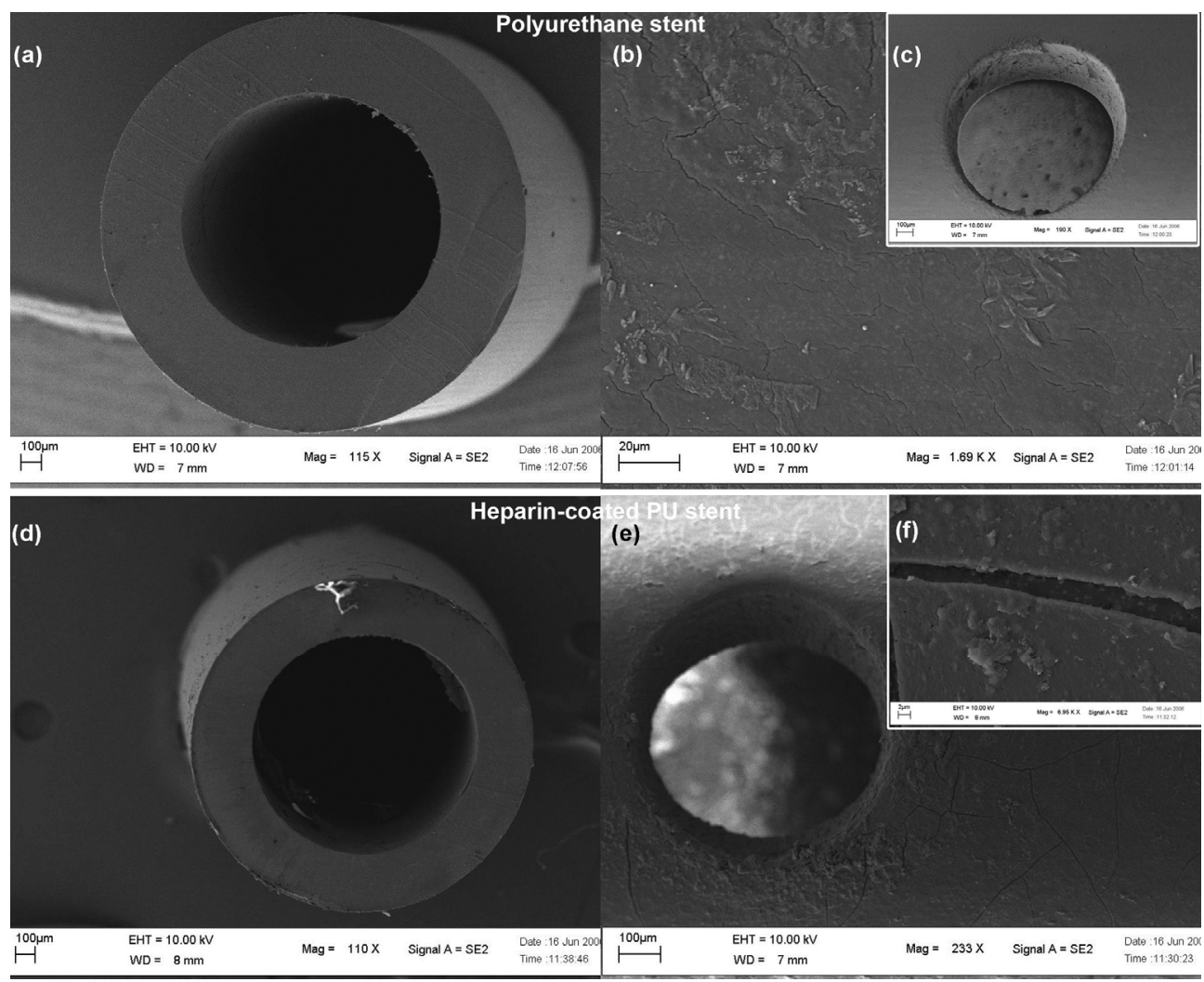

Figure 11. The surface morphology of PU and heparin-coated stents indwelled bilaterally into the same patient for one month.

In the second case, we examined the stents after bilateral indwelling into a patient presenting a recidivist calculosis into both her kidneys. In particular the patient had multiple lithiasis ( 3 calculus) at the lower calyx of the left kidney. Stenting into both the ureters was carried out after removal of stones by endoscopic lithotripsy with holmium laser; however residual lithiasis was still present. The DLC-treated stent was positioned into the left ureter, to verify its performance after calculus removal. The PU stent was indwelled at the same time into the right ureter. After one month both stents were removed, due to patient low tolerance. This patient underwent two repetitive stents indwelling, always having pain and very low tolerance towards every catheter. 
Figure 12 shows the high degree of encrustation, in particular concerning the PU stent. In particular, the encrustation was thicker than $40 \mu \mathrm{m}$ and was composed of bacterial biofilm and inorganic salts, such as brushite $\left(\mathrm{CaHPO}_{4} \cdot 2 \mathrm{H}_{2} \mathrm{O}\right)$ and sodium chloride.

In contrast, the encrustation level of the DLC-coated stent was not so compact and uniform as in the untreated PU stent. It was therefore assumed that the presence of the DLC surface modification prevented partially the encrustation deposition and the bacterial adhesion, despite the pathology of the patient. In particular the DLC-coating seemed to guarantee the stent lumen free for urine drainage (Figure 12.c).

From EDS analysis, no particular inorganic compounds were identified on the surface of the DLC-coated stent (data not shown).

For the overall 20 stents indwelled bilaterally for one month (see Table 1) it was concluded that both surface treatments effectively prevented or at least decreased the levels of encrustation by both bacterial biofilm and inorganic compounds, with respect to the pure PU catheter. It was found that the highest incidence of encrustations took place at the inner surface of the catheter.
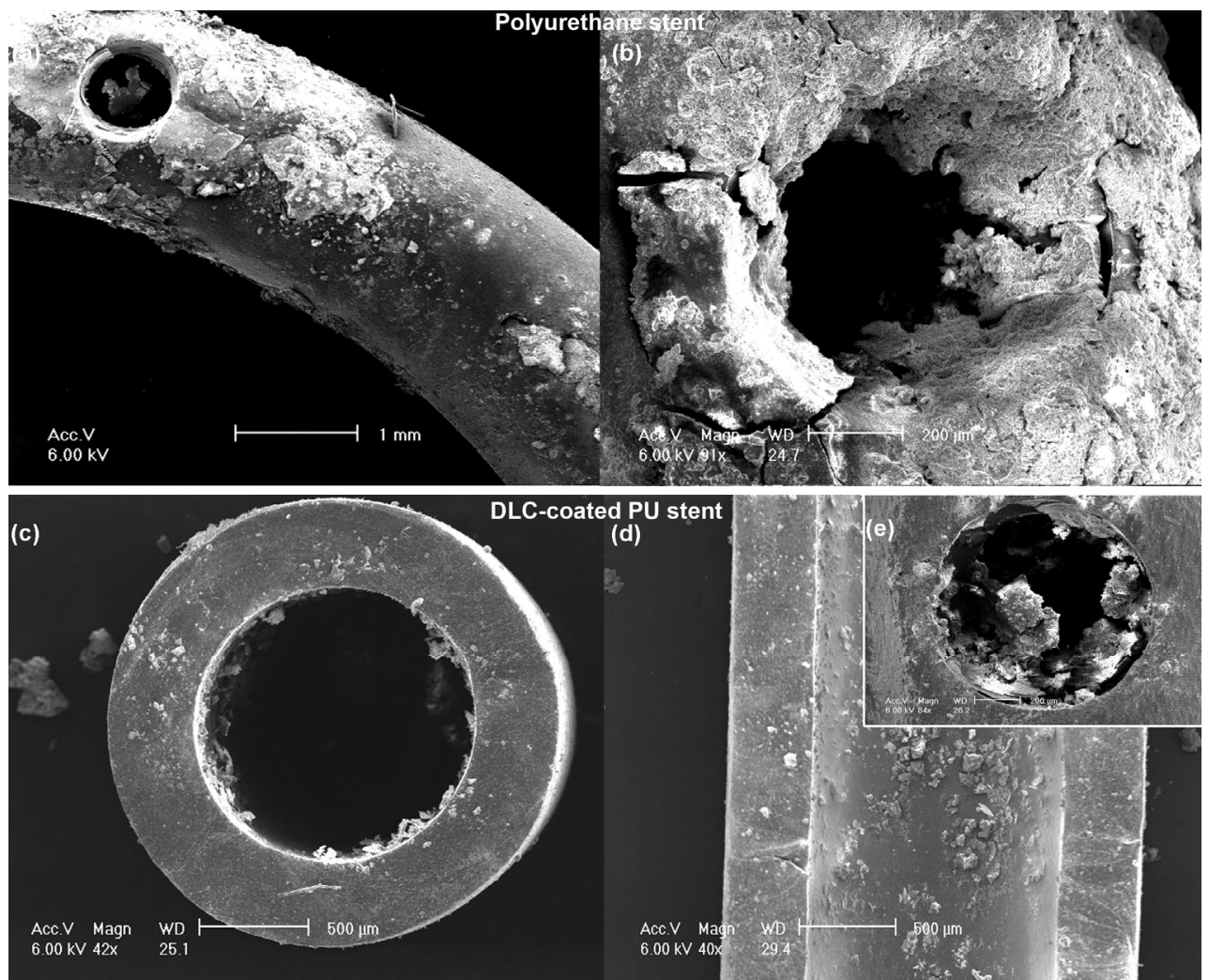

Figure 12. FESEM images of PU and DLC-coated ureteral stents indwelled bilaterally for one month into the same patient, suffering from recidivist calculosis. 


\subsection{Results summary}

Summarizing the results obtained upon stent indwelling into 59 patients, some statistical considerations can be drawn. Considering only the surface-treated stents, the level of bacterial biofilm stabilized after three months of indwelling (incidence of the encrustation on the total amount of heparin-coated stents analyzed: $81.3 \%$ ), remaining almost constant for longer indwelling time $(78.6 \%)$. The incidence of sodium chloride, silica and salts of magnesium and potassium increased with the indwelling time or due to the recidivist calculosis of the patient. Interestingly, the highest levels of calcium oxalate and brushite were found at the surface-modified stents indwelled for 3 months into stone-former patients (75\% for both compounds). For indwelling times longer than 3 months, the levels of calcium oxalate and brushite decreased (42.9\% for calcium oxalate and $57.1 \%$ for brushite).

Concerning the PU stents, high contents of sodium chloride and other salts were generally observed in high percentages (up to $100 \%$ ), despite the indwelling time and the patient pathology. The highest percentages of both bacterial biofilm and calcium oxalate were observed after already 3 months of indwelling time (85\% of biofilm , $50 \%$ of calcium oxalate, $43 \%$ of brushite).

\section{Conclusion}

In the present chapter we have summarized the results from the characterization of uncoated PU, heparin- and DLC-coated PU ureteral stents after indwelling into 59 patients. Field Emission Scanning Electron Microscopy, Energy Dispersive Spectroscopy, Infrared Spectroscopy were used to characterize both inner and outer catheter surfaces.

With these techniques two kinds of deposits were detected at the stent surfaces:

1. inorganic compounds, like calcium oxalate, sodium chloride, brushite and salts of potassium, magnesium and phosphorous;

2. bacterial biofilm;

In addition, the thickness of the encrustations was estimated at the stent cross sections.

We have divided the obtained data according to their indwelling time, the unilateral or bilateral indwelling and the patient's tendency to form calculus (stone-former or not).

Concerning the non-stone former patients, the encrustation levels were lower in the surfacetreated stents with respect to the untreated PU surfaces. In particular, concerning the bilaterally indwelled stents, a direct comparison between the surface properties of the stent in preventing encrustation was clearly observed. It was indeed assessed that the formation of bacterial biofilm was lower at the surface-treated catheters, whereas the precipitation of inorganic compounds were not completely inhibited. We attributed reduction of the biofilm to the presence of the surface treatments (heparin- or DLC-coatings) on the polyurethane surface. No relevant differences were found between the two surface modifications in preventing the stent encrustation upon indwelling. It was also observed that both treated and untreated PU stents did not degrade in this kind of patients. 
These considerations were no more valid when the patient was a stone-former. Indeed, the recidivist calculosis induced a continuous deposition of biofilm and salts at the stent surface, thus strongly reducing the effect of the surface modification in preventing encrustation. In addition, the stents were more stiff and brittle after already one month of insertion, thus inducing patient discomfort or pain.

It was noteworthy that both the formation of biofilm and inorganic encrustation and the success of the stent indwelling depended more significantly on the patient's pathology (i.e. stone former or not) than on the indwelling time. For these reasons, implanting a stent for a period of time longer than one month was feasible. A surface-treated polyurethane stent was also preferable with respect to the untreated PU one. However, frequent stent exchange, regardless of the surface treatment, is a general recommendation for patients suffering from a recidivist calculosis.

As a future outlook, new studies should expand in the direction of bio-degradable drugeluting polymeric stents. The preparation of such highly engineered ureteral stents should require the following properties:

- $\quad$ Providing effective urine drainage without the formation of bacterial biofilm;

- Being biocompatible and preventing cytotoxicity;

- Being fully biodegradable to avoid the complications of the stent removal and the subsequent patient hospitalization;

- Effectively incorporating a therapeutic agent;

- Showing the capability to release the drug in a time-controlled manner;

- Releasing the required amount of drug, between the minimum effective level and the minimum toxic one;

- Preventing the patient discomfort and pain;

- Being deliverable and visible, with adequate radiopacity (or the presence of radiopaque markers) to enable precise positioning under X-ray fluoroscopic guidance.

We envision that such a commitment will require a strong interdisciplinary background, thus combining the fields of material science and technology to the clinical and endourological requirements.

\section{Author details}

Valentina Cauda

Center for Space Human Robotics CSHR@Polito, Italian Institute of Technology, Turin, Italy

Furio Cauda

Urology division, Koelliker Hospital,Turin, Italy

\section{Acknowledgement}

Cook Ireland Ltd. is gratefully acknowledged for the financial support and the stent supply. 


\section{References}

Anne Thomson, L., et al. (1991). Biocompatibility of diamond-like carbon coating.Biomaterials Vol. 12, No 1,pp. 37-40.

Appelgren, P., et al. (1996). Surface heparinization of central venous catheters reduces microbial colonization in vitro and in vivo: Results from a prospective, randomized trial.Crit. Care Med. Vol. 24, pp. 1482-1489.

Arshad, M., et al. (2006). Applications and complications of polyurethane stenting in urology.J. Ayub. Med. Coll. Abbottabad Vol. 18, No 2,pp. 69-72.

Cadieux, P. A., et al. (2006). Triclosan loaded ureteral stents decrease proteus mirabilis 296 infection in a rabbit urinary tract infection model.J. Urol. Vol. 175, No 6,pp. 2331-2335.

Cauda, F., et al. (2009). Coated Ureteral Stent. Biomaterials and tissue engineering in urology. P. J. Denstedt and P. A. Atala. London, Woodhead Publishing Ltd.

Cauda, F., et al. (2008). Heparin Coating on Ureteral double J Stents Prevents encrustations: an In Vivo Case Study.J. Endourology Vol. 22, No 3,pp. 465-472.

Cho, Y. H., et al. (2001). Prophylactic efficacy of a new gentamicin-releasing urethral catheter in short-term catheterized rabbits.BJU International Vol. 87, No 1,pp. 104-109.

Cormio, L., et al. (2001). Bacterial adhesion to urethral catheters: Role of coating materials and immersion in antibiotic solution.Eur. Urol. Vol. 40, No 3, pp. 354-359.

Costerton, J. W. (2007). The Biofilm Primer. Springer, Hiedelberg. Pp 1- 200

Gorman, S. P. and A. D. Woolfson (2002). Novel biomimetic and bioactive silicones.Med. Device Technol. Vol. 13, No 7,pp. 14-15.

Grill, A. (1999). Diamond-like carbon: state of the art.Diamond and Related Materials Vol. 8, 428-434.

Hildebrandt, P., et al. (1999). Immobilisiertes heparin als inkrustierungresistente Beschichtung auf urologischen implantaten.Biomed. Techn. Vol. 42, pp. 123-124.

Jansen, B., et al. (1993). Bacterial adherence to hydrophilic polymer-coated polyurethane stents.Gastrointest. Endosc. Vol. 39, No 5,pp. 670-673.

John, T., et al. (2007). Antibiotic Pretreatment of Hydrogel Ureteral Stent.J. Endourology Vol. 21, No 10,pp. 1211-1216.

Laube, N., et al. (2006). Plasma-deposited carbon coating on urological indwelling catheters : Preventing formation of encrustations and consecutive complications.Urologe A. Vol. 45, No 9,pp. 1163-1169.

Laube, N., et al. (2007). Diamond-like carbon coatings on ureteral stents-a new strategy for decreasing the formation of crystalline bacterial biofilms?J. Urol. Vol. 177, No 5,pp. 1923-1927.

Leung, J. W., et al. (1992). Decreased bacterial adherence to silver-coated stent material: an in vitro study.Gastrointest. Endosc. Vol. 38, No 3,pp. 338-340.

Leung, J. W., et al. (2001). Effect of antibiotic-loaded hydrophilic stent in the prevention of bacterial adherence: A study of the charge, discharge, and recharge concept using ciprofloxacin.Gastrointest. Endosc. Vol. 53, No 4,pp. 431-437. 
Lingeman, J. E., et al. (2003). Use of a temporary ureteral drainage stent (TUDS) after uncomplicated ureteroscopy: results from a phase II clinical trial.J. Urol. Vol. 169, No 5,pp. 1682-1688.

Mardis, H. K., et al. (1993). Comparative evaluation of materials used for internal ureteral stents.J. Endourol. Vol. 7, No 2,pp. 105-115.

Multanen, M., et al. (2000). Bacterial adherence to ofloxacin-blended poly-lactone-coated self-reinforced L-lactic acid polymer urological stents.BJU International Vol. 86, No,pp. 966-969.

Olweny, E. O., et al. (2002). Evaluation of the use of a biodegradable ureteric stent after retrograde endopyelotomy in a porcine model.J. Urol. Vol. 167, No 5,pp. 2198-2202.

Piper, J. (1946). The anticoagulant effect of heparin and synthetic polysaccharidepolysulphuric acid esters.Acta Pharmacol. Vol. 2, pp. 138-148.

Raad, I., et al. (1997). Central Venous Catheters Coated with Minocycline and Rifampin for the Prevention of Catheter-Related Colonization and Bloodstream Infections.Ann. Intern. Med. Vol. 127, No 4,pp. 267-274.

Reid, G. (2001). Oral fuoroquinolone theraphy results in drug adsorption on ureteral stents and prevention of biofilm formation.Int. J. Antimicr. Ag. Vol. 17, pp. 317-320.

Roy, R. K. and K.-R. Lee (2007). Biomedical applications of diamond-like carbon coatings: A review.J. Biomed. Mater. Res. Part B: Appl. Biomater. Vol. 83, No B,pp. 72-84.

Ruggieri, M. R., et al. (1987). Reduction of bacterial adherence to catheter surface with heparin.J. Urol. Vol. 138, pp. 423-426.

Tenke, P., et al. (2004). Bacterial biofilm formation on urologic devices and heparin coating as preventive strategy Int. J. Antimicr. Ag. Vol. 23, No S1,pp. 67-74.

Voevodin, A. A. and M. S. Donley (1996). Preparation of amorphous diamond-like carbon by pulsed laser deposition: a critical review.Surface and Coatings Technology Vol. 82, No 3,pp. 199-213.

Warren, J. W., et al. (1994). Long-term urethral catheterization increases risk of chronic pyelonephritis and renal inflammation.J. Am. Geriat. Soc. Vol. 42, No 12,pp. 1286-1290.

Zdrahala, R. J. and I. J. Zdrahala (1999). Biomedical application of polyurethanes: A review of past promises, present realities, and a vibrant future.J. Biomater. Appl. Vol. 14, pp. 67-90. 